\title{
Impact of Small Molecules Immunosuppressants on P-Glycoprotein Activity and T-cell Function
}

\author{
Inés Llaudó ${ }^{1}$, Linda Cassis ${ }^{1}$, Joan Torras ${ }^{1}$, Oriol Bestard ${ }^{1}$, Marcel·la Franquesa ${ }^{1}$, Josep M. Cruzado ${ }^{1}$, Gema Cerezo ${ }^{1}$, \\ Esther Castaño $^{2}$, Jordi Pètriz ${ }^{3}$, Immaculada Herrero-Fresneda ${ }^{1}$, Josep M. Grinyó ${ }^{1}$ and Núria Lloberas ${ }^{1}$. \\ ${ }^{1}$ Nephrology Department and Laboratory of Experimental Nephrology, Bellvitge University Hospital, Hospitalet de \\ Llobregat, Spain. \\ ${ }^{2}$ Department of Scientific and Technical Services, University of Barcelona, Hospitalet de Llobregat, Spain. \\ ${ }^{3}$ Vall d'Hebron Research Institute, Barcelona, Spain.
}

Received, May 5, 2012; Accepted, July 13, 2012; Published, July 15, 2012.

\begin{abstract}
Purpose. P-glycoprotein (Pgp) is a member of the ABC-transporter family that transports substances across cellular membranes acting as an efflux pump extruding drugs out of the cells. Pgp plays a key role on the pharmacokinetics of several drugs. Herein, we have studied the effects of immunosuppressants on Pgp function, assessing rhodamine-123 (Rho123) uptake and efflux in different Tcell subsets. Methods. Different immunosuppressants such as Cyclosporine (CsA), Rapamycin (Rapa) and Tacrolimus (Tac) were used to assess the in vitro effect on Pgp function of main T-cell subsets among healthy volunteers. We measured Rho123 uptake, efflux and kinetic of extrusion in CD4 ${ }^{+}$and $\mathrm{CD} 8^{+}$subsets by flow cytometry. Antigen-specific memory T-cell responses were assessed by measuring T-cell proliferation and cytokine secretion using an allogeneic mixed lymphocyte reaction. Results. Rho123 uptake in groups treated with CsA and CsA+Rapa was significantly decreased compared to non-treated group and the other immunosupressants in both T cells subsets. Pgp activity was also reduced in CsA and CsA+Rapa compared to the other immunosupressants but it was only significant in the CsA group for $\mathrm{CD} 8^{+}$subset. Kinetic extrusion of Rho123 by Pgp in all groups was faster in $\mathrm{CD}^{+} \mathrm{T}$ cells. All immunosuppressants and the specific Pgp inhibitor PSC833 diminished antigen-primed T-cell proliferation, especially CD8 ${ }^{+} \mathrm{T}$-cell subset. Conclusions. Our data indicate that small molecules immunosuppressants, especially CsA, inhibit Pgp activity and $\mathrm{T}$-cell function being the $\mathrm{CD} 8^{+} \mathrm{T}$ cells more susceptible to this effect. These findings support the importance of Pgp when designing combined immunosuppressive regimens.
\end{abstract}

This article is open to POST-PUBLICATION REVIEW. Registered readers (see "For Readers") may comment by clicking on ABSTRACT on the issue's contents page.

\section{INTRODUCTION}

The MDR1 gene product P-glycoprotein (Pgp) is the most studied membrane protein of the large mammalian $\mathrm{ABC}$ transporter family (1). These plasma membrane proteins play a major role in determining drug uptake, distribution and excretion processes, and they play a key role in drug pharmacokinetics (2). Pgp has been described as a possible mediator to explain variability in toxicity patterns associated with immunosuppressive therapies (3). There is an increasing interest in the precise role of Pgp in T lymphocyte activation and antigen presenting cell function. Pgp actively extrudes a wide variety of structurally diverse cytotoxic compounds out of the cell. It is widely expressed in the epithelial cells of the kidney, liver and intestine, and in the endothelial cells of brain and placenta (4). Also, its expression has been described in lymphoid cell populations from human bone marrow and peripheral blood (5). Specifically, it has been shown on the membrane of pluripotent stem cells, monocytes, dendritic cells, $\mathrm{CD} 4^{+}$and $\mathrm{CD} 8^{+} \mathrm{T}$ lymphocytes, NK cells, and B lymphocytes, suggesting that Pgp may influence cell-mediated immune responses (6-9).

$\mathrm{ABC}$ transporters may be therapeutic targets in organ transplantation, but the importance of Pgp in immune function still remains unclear (1013). Up-regulation of Pgp in T-cell populations could result in decreasing intracellular drug concentrations rendering these cells resistant to immunosuppressive therapy despite appropriate plasma drug exposure (14).

\footnotetext{
Corresponding Author: Inés Llaudó Department of Experimental Nephrology, Pabelló Govern s/n, $4^{\text {th }}$ floor, Lab 4122, University Hospital of Bellvitge, 08907 L'Hospitalet de Llobregat, Barcelona, Spain; E-mail: illaudo@ub.edu
} 
Pgp and cytochrome P450 3A4 (CYP3A4) are determinants of the bioavailability of widely used immunosuppressants such as cyclosporine A (CsA), tacrolimus (FK506/Tac) and sirolimus (Rapa) (15). These immunosuppressants themselves, as substrates and/or inhibitors of Pgp, could alter the bioavailability of many concomitantly drugs being potentially important in drug interactions $(16,17)$. CsA, remains as an important immunosuppressive drug in solid organ transplantation and has been described as a potent Pgp inhibitor (18). Conversely, the role of Tac and Rapa on Pgp function still remains undefined. Tac is 10-100 times more potent than CsA as an immunosuppressive agent (19) with effective concentrations of $0.003-0.019 \mu \mathrm{M}$ compared to $0.083-0.208 \mu \mathrm{M}$ for CsA $(20,21)$. Rapa is structurally similar to Tac that modulates the immune response at a different level to calcineurin inhibitors (CNIs). The combination of CNIs, either CsA or Tac, with mTOR inhibitor (mTORi) exert a potent immunosuppressive effect, but potentiates CNI-related nephrotoxicity $(18,22)$.

In a previous study (23) we investigated the impact of the association of Rapa with Tac or CsA on Pgp expression in a rat nephrotoxicity model, showing a renal over-expression related to CsA exposition. The aim of the current study was to evaluate the effect of several CNIs and mTORi on Pgp function evaluated by Rho123 uptake and efflux measurements in $\mathrm{CD}^{+}$and $\mathrm{CD} 8^{+} \mathrm{T}$-cell subsets.

Therefore, CsA in monotherapy and associated with Rapa decreases Pgp activity in $\mathrm{CD} 8^{+} \mathrm{T}$-cells. Immunosuppressive drugs and Pgp inhibitor significantly reduced the $\mathrm{CD}^{+} \mathrm{T}$-cell proliferation and cytokine release. The Pgp inhibition could be a novel therapeutic target to avoid allograft rejection in solid organ transplantation.

\section{MATERIAL AND METHODS}

\section{Reagents and antibodies}

The following monoclonal antibodies were used to characterize cell subpopulations: mouse antihuman CD4-APC, mouse anti-human CD3-APC and mouse anti-human CD8-PE were purchased from eBioscience (San Diego, CA, USA). PSC833 was kindly provided by Novartis (Basel, Switzerland). FK506 (Tacrolimus) was a gift from Astellas Pharma Inc. Cyclosporine and rapamycin were purchased from Sigma-Aldrich (Madrid, Spain) as 7-Aminoactinomycin D (7-AAD).
Appropriate stock solutions of drugs were prepared in culture medium RPMI 1640 (Biological Industries, Israel) and diluted in 100\% dehydrated ethanol. Phosphate Buffered Saline (PBS) was obtained from PAA (Cambridge, UK). Biotarget-1 is a specific culture medium for lymphocytes which was used; it was purchased from Biological Industries. Rho123 was purchased from Invitrogen, Molecular Probes Inc., USA as 5,6-carboxyfluorescein diacetate succinimidyl ester (CFSE). Cytometric Bead Array (CBA) Human Th1/Th2/Th17 kit was purchased from BD.Biosciences Pharmingen (San Diego, CA).

\section{Isolation of peripheral blood lymphocytes}

Peripheral blood mononuclear cells (PBMCs) were isolated from healthy volunteers $(\mathrm{n}=8)$ by Ficoll-Paque Plus (GE Healthcare Bio Sciences AB, Uppsala, Sweden) density gradient centrifugation according to the manufacturer's instructions. Cells were then washed and resuspended in Biotarget-1 medium supplemented with $1 \%$ L-Glutamine, $1 \%$ Sodium Pyruvate and $1 \%$ Pen-Streptomycin. Cell viability was confirmed by trypan blue exclusion and was always greater than 90\%. Lymphocytes were frozen in freezing medium as described previously (24).

The study groups were defined according to the different immunosuppressive drugs used: cyclosporine (CsA 2.5 $\mu \mathrm{M}$ ), rapamycin (Rapa $0.25 \mu \mathrm{M})$, tacrolimus (Tac $0.1 \mu \mathrm{M})$ and two more groups with Rapa associated with CNIs. A nonstimulated, non-treated (negative control) and non-treated stimulated (positive control) were added ( $\mathrm{n}=8$ for group). Stimulated cells are exposed to allogeneic T-cell depleted lymphocytes. Drug concentrations were obtained from Pawarode et al. choosing those in the upper level (25).

Informed consent was signed from each healthy volunteer after the nature and possible consequences of the study were fully explained. Written informed consent was obtained in accordance with the Hospital Universitari de Bellvitge Ethic Committee.

\section{Flow cytometry analysis}

Flow cytometry was performed on a FACSCalibur flow cytometer (Becton, Dickinson and Company, BD) with four-color analysis. The four optical filters on the FACS Calibur were F1 1 at $530 \pm 15 \mathrm{~nm}$ (for Rho123 uptake), Fl 2 at $585 \mathrm{~nm}$ (for CD8-PE), Fl 3 at $670 \mathrm{~nm}$ (for 7-AAD) and Fl 
4 at $660 \mathrm{~nm}$ (for CD4-APC). Acquisition was stopped when 10,000 gated events were collected in the fluorescence cell count histogram. Gating was based on forward scatter and side scatter dot plots by encircling populations with amorphous regions and then excluding dead cells (life gate) by 7-ADD counterstaining (under dyecompatibility conditions). We monitored the linearity of the flow cytometer measurements daily to show the results in accurate standard fluorescence units by using calibration standard beads (K0110, Dako, Glostrup, Denmark) to decrease the variation in flow results and to provide the reference dye fluorescence for quantitative measurements. These quantitative measurements included mean fluorescence intensity (MFI) in linear values, which were transformed, according to the manufacturer's instructions, into calibrated values of molecules of equivalent soluble fluorochrome (MESF). A manual calibration curve $(\log =a \times \log +b)$ was constructed to convert fluorescence measurements to MESF units. Data were analyzed using Cell Quest software.

\section{Measurement of Pgp function by flow cytometry}

Pgp function was estimated using three parameters: 1) considering that $\mathrm{ABC}$ transporters such as $A B C B 1$ may handle not only the efflux but also the influx of their substrates, the intracellular uptake of Rho123 was the first evaluated; 2) Cells pump out Rho123 by passive diffusion through Pgp (26), so Rho123 efflux assays were used to evaluate Pgp activity; and 3) The time needed to efflux $50 \%$ of Rho123 out the cells ( $t_{50}$; average rate of drug efflux) was used to define the efflux kinetic parameter (Fig. 1).

\section{Intracellular Rho123 uptake}

The intracellular Rho123 uptake was established after $30 \mathrm{~min}$ of co-incubation of cells with Rho123. Human PBMCs $\left(1 \times 10^{6}\right.$ cells $)$ were suspended in $1 \mathrm{ml}$ of supplemented Biotarget-1 and incubated $\mathrm{o} / \mathrm{n}$ at $37^{\circ} \mathrm{C} 5 \% \mathrm{CO}_{2}$ with the different immunosuppressive drugs. Finally, cells were washed with PBS and resuspended in $1 \mathrm{~mL}$ Biotarget-1. To allow Rho123 uptake, cell suspension was incubated with Rho123 at a final concentration of $200 \mathrm{ng} / \mathrm{mL}$ for $30 \mathrm{~min}$ at $37^{\circ} \mathrm{C}$ $5 \% \mathrm{CO}_{2}$, avoiding light exposure, in the presence or absence of PSC833 $(10 \mu \mathrm{M})$. PSC833 was used as a Pgp-specific competitive inhibitor to estimate the amount of Rho123 accumulated after Pgp inhibition. At the end of the uptake period, cells were kept on ice to stop Pgp activity and then washed with ice-cold PBS without $\mathrm{Ca}^{2+}$ and $\mathrm{Mg}^{2+}$ to remove extra cellular Rho123. PSC833 was also maintained during the washes to avoid periods of non-inhibition.

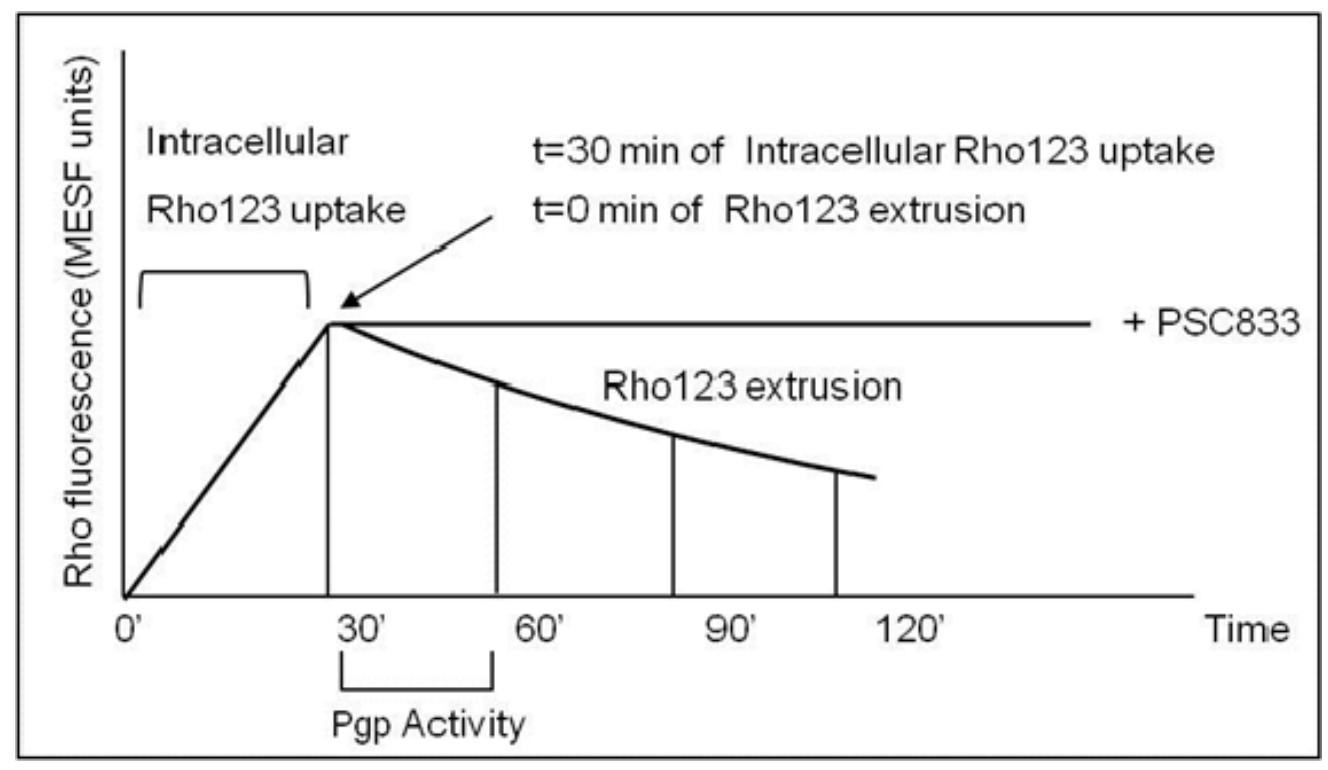

Figure 1. Pgp function measured by flow cytometry. 1) Intracellular Rho123 uptake (30 min). 2) Pgp activity (Rho123 uptake) was measured after the first $30 \mathrm{~min}$. 3) Kinetic profile of Rho123 extrusion ( $\mathrm{t}_{50}$; average rate of drug efflux) was evaluated at different time points $(0,30,60,90$ and $120 \mathrm{~min})$ according to each immunosuppressive treatment. 
After washing, $0.5 \times 10^{6}$ cells of each treatment were stained for phenotypic expression of surface $\mathrm{CD}^{+}$and $\mathrm{CD} 8^{+}$. After 20 min incubation on ice, cells were washed with PBS supplemented with $2 \%$ Fetal Bovine Serum and immediately acquired on the flow cytometer. The remaining half of the cells was resuspended in $1 \mathrm{ml}$ Biotarget-1 without Rho123 to allow efflux of the dye out of the cell, for $120 \mathrm{~min}$ at $37^{\circ} \mathrm{C} 5 \% \mathrm{CO}_{2}$. At the end of the efflux incubation, cells were kept on ice to prevent further reaction and stained for phenotypic expression of surface $\mathrm{CD}^{+}$and $\mathrm{CD} 8^{+}$and then immediately acquired on the cytometer. To detect cells with membrane damage (necrotic cells) 7-AAD was added to all samples and incubated for $15 \mathrm{~min}$ on ice, avoiding light exposure prior to flow cytometry analysis in order to exclude dead cells from the analysis.

\section{Determination of Pgp activity}

Basal Pgp activity was estimated by Rho123 fluorescence at $30 \mathrm{~min}$ after an established loading period considered enough time to achieve the intracellular steady-state level but not so long as to induce de novo activity (27). In our experiments, Pgp activity was estimated on the kinetic of Rho123 uptake and extrusion using Rho123 fluorescence (MESF units).

\section{Kinetic of Rho123 extrusion}

Different time points $(0,30,60,90$ and $120 \mathrm{~min})$ were chosen to evaluate the early, the linear and the late phases of the efflux for $\mathrm{CD} 4^{+}$and $\mathrm{CD} 8^{+}$ T-cell subsets. For kinetic measurements we calculated the time needed to efflux $50 \%$ of Rho123 out of cells ( $t_{50}$; average rate of drug efflux).

\section{Antigen-specific memory T-cell proliferation assay by flow cytometry}

To asses the effect of the different immunosupressive agents and the specific Pgp inhibitor (PSC833) on memory/effector T-cell responses an alloantigen-specific memory T-cell co-culture was done. For this purpose a short term antigen-specific memory $\mathrm{T}$-cell line was produced by mixing $2 \times 10^{5}$ PBMC from a responder subject with $2 \times 10^{5}$ stimulator T-cell depleted (Rosette Sep Human CD3 Depletion Cocktail Kit; Stem Cell Technologies, Grenoble, France) and irradiated (40 Gy) PBMCs obtained from an allogeneic subject. Cells were incubated in a final volume of $200 \mu \mathrm{L}$ in a complete medium consisted of RPMI-1640 supplemented with $10 \%$ heatinactivated FBS, 1\% L-Glutamine and 1\% Pen-
Streptomycin in round-bottom 96-well cell culture plates (Costar, Cambridge, MA). The plates were then placed in a humidified $37^{\circ} \mathrm{C}$, $5 \% \mathrm{CO}_{2}$ incubator for 6 days. Then, cells were harvested and incubated $\mathrm{o} / \mathrm{n}$ with the different immunosuppressants and PSC833 at the same concentrations than Pgp function assay. $2 \times 10^{5}$ of the resulting primed responder PBMCs for each treatment were labeled with succinimidyl ester of carboxyfluorescein diacetate (CFSE $5 \mu \mathrm{M})$ as described (28) and were plated again in duplicate wells with the same stimulator cells in a ratio of 1:1 for 5 days in the same conditions. Culture supernatants were harvested after this period of time, snap frozen and stored at $-80^{\circ} \mathrm{C}$ until analysis. As positive responder control, PBMCs were stimulated with $1 \mu \mathrm{g} / \mathrm{ml}$ phytohemagglutinin (PHA). Proliferation of responder cells was evaluated by FACS analysis of T-cells subsets using monoclonal antibodies specific for CD3, CD4 and CD8. Experiments are representative of four independent assay.

\section{Cell cytokine analysis by Flow Cytometry}

Cytokine secretion into supernatants by PBMCs was analyzed by flow cytometry with a fluorescent bead assay (CBA Human Th1/Th2/Th17 kit) after staining according to the manufacturer's instructions. Cytokines quantification was performed on non-treated stimulated and treated with immunosuppressants and the specific Pgp inhibitor (PSC833) in PBMCs after MLR. Experiments are representative of three independent assays.

\section{STATISTICAL ANALYSIS}

All data are presented as mean \pm SE. Group means were compared with analysis of variance (ANOVA) for parametric values, followed by post hoc Fisher's test. All $p$-values were twotailed and a $p$-value of less than 0.05 was considered statistically significant.

\section{RESULTS}

Intracellular Rho123 uptake of $\mathrm{CD4}^{+}$and $\mathrm{CD8}^{+}$T-cell subsets

Intracellular Rho123 uptake in CsA groups (CsA and CsA+Rapa) was significantly decreased compared to non-treated group and the other immunosupressants in $\mathrm{CD}^{+}$and $\mathrm{CD} 8^{+} \mathrm{T}$ cells. Considering the intracellular Rho123 uptake after 30 minutes of incubation as the baseline 
intracellular value, $\mathrm{CD} 8^{+} \mathrm{T}$ cells showed higher Rho123 uptake than $\mathrm{CD}^{+}$(Fig. 2).

\section{Pgp activity of $\mathrm{CD4}^{+}$and $\mathrm{CD8}^{+} \mathrm{T}$-cell subsets}

The study of the kinetics of Rho123 extrusion in T-cell population displayed a noticeable slower efflux in CsA and CsA+Rapa compared to the others immunosupressants at 60,90 and 120 minutes $(p<0.001)$. In contrast, macrolides-treated $\mathrm{T}$ cells showed a similar extrusion speed to the non-treated group (Fig. 3).

Thereafter, we further analysed the kinetic pattern of Rho123 efflux on $\mathrm{CD}^{+}$and $\mathrm{CD} 8^{+} \mathrm{T}$ cell subsets. As shown in figure $4, \mathrm{CD}^{+} \mathrm{T}$ cells displayed slower extrusion rate than $\mathrm{CD} 8^{+} \mathrm{T}$ cells, showing a similar kinetic than Rho 123 uptake. After two hours of efflux, there was still more than $50 \%$ of the Rho123 in the $\mathrm{CD}^{+} \mathrm{T}$ cells, whereas in $\mathrm{CD}^{+} \mathrm{T}$ cells $70-80 \%$ of Rho123 had already been extruded. In both T-cell subsets additional treatments with PSC833 increased fluorescence (data not shown) corroborating the role of Pgp on T cells. Normalized values of
Rho123 extrusion at different time-points expressed in percentages are depicted in table 1.

We observed significant differences in Rho123 extrusion between non-treated group and CsA alone and CsA+Rapa for CD8 T-cell subset. On the other hand, in CD8 T cells, Pgp activity in CsA group was significantly lower than macrolides alone and associated groups (Rapa,Tac and Tac+Rapa). In $\mathrm{CD}^{+}{ }^{+} \mathrm{T}$ cells, CsA groups showed less Pgp function compared with all groups but no significant differences were found between any group (Fig. 5).

Pgp activity calculated as $t_{50}$ (average rate of drug efflux) on $\mathrm{CD}^{+}$and $\mathrm{CD} 8^{+} \mathrm{T}$-cell subsets displayed a similar kinetic pattern than Pgp activity measured by Rho123 extrusion. Rho123 $\mathrm{t}_{50}$ corroborated faster efflux time in $\mathrm{CD} 8^{+}$subset than in $\mathrm{CD}^{+}$(Fig. 6). Both $\mathrm{CD} 4^{+}$and $\mathrm{CD} 8^{+} \mathrm{T}$ cells showed longer time to efflux $50 \%$ of the drug in the CsA groups (alone and associated with Rapa) than the other treatments and the nontreated group confirming the inhibitory effect of CsA.

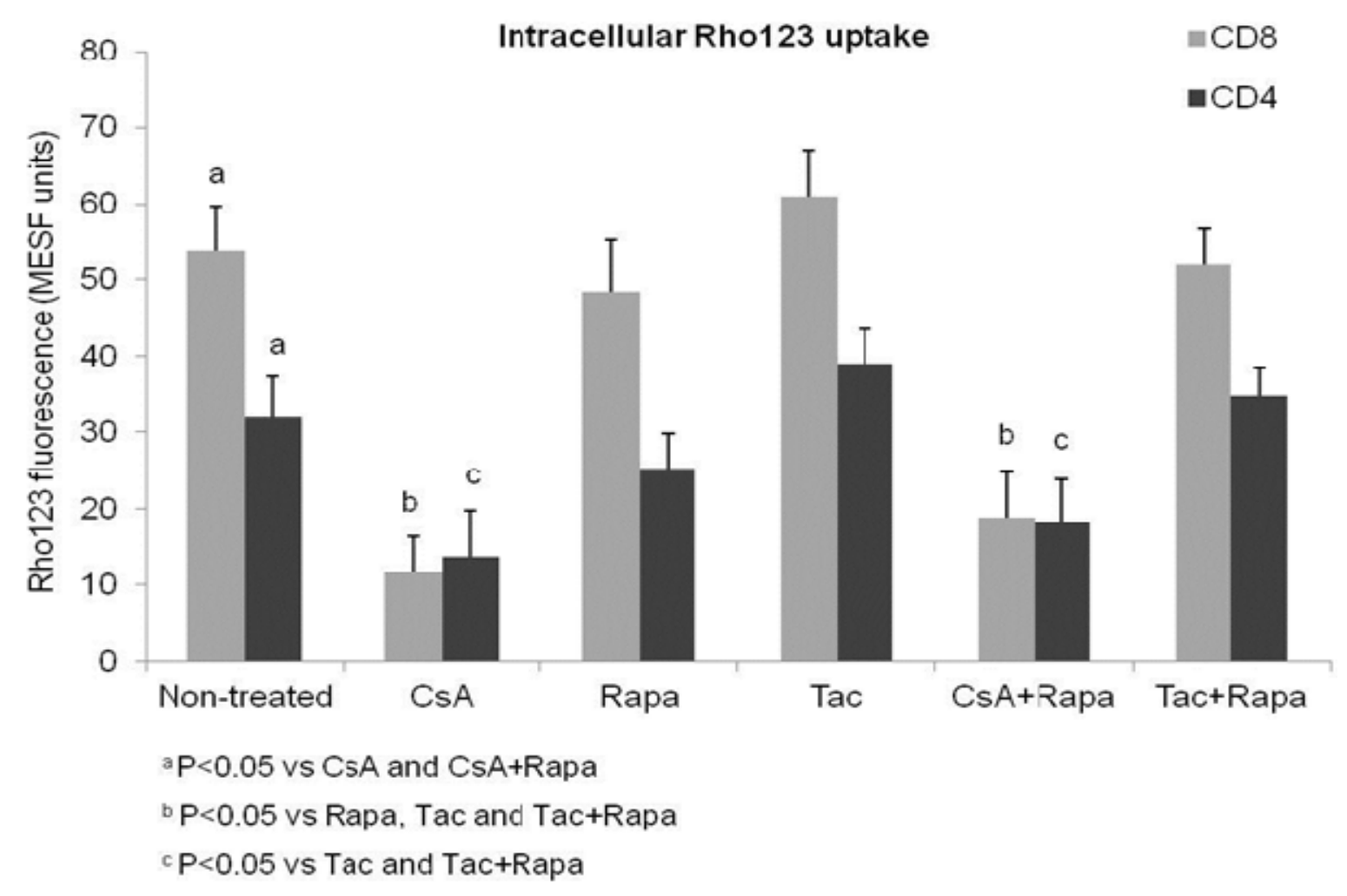

Figure 2. Intracellular Rho1 23 uptake by flow cytometry analysis in $\mathrm{CD}^{+}$and $\mathrm{CD} 8^{+}$subsets. Human PBMCs $\left(1 \times 10^{6}\right.$ cells) were pre-incubated at $37^{\circ} \mathrm{C} 5 \% \mathrm{CO}_{2} \mathrm{o} / \mathrm{n}$ with the different immunosuppressive drugs, and Rho123 uptake was measured after 30 min of co-incubation of cells with Rho123. Values are means (MESF) \pm SE. N=8 different subjects for each group. 
Table 1. Rho123 fluorescence in $\mathrm{CD}^{+} / \mathrm{CD}^{+} \mathrm{T}$ cells from each immunosuppressive group after 30, 60, 90 and 120 minutes efflux in comparison with minute $0(100 \%)$. The results are presented as normalized values. Data are in percentage as mean \pm SE. Each experiment was performed from blood of healthy volunteers. $\mathrm{N}=8$ different subjects for each group.

\begin{tabular}{|c|c|c|c|c|c|c|}
\hline & Non-treated & Rapa & CsA & Tac & CsA+Rapa & Tac+Rapa \\
\hline \multicolumn{7}{|l|}{$\mathrm{CD}^{+}$} \\
\hline $0 \mathrm{~min}$ & 100 & 100 & 100 & 100 & 100 & 100 \\
\hline $30 \mathrm{~min}$ & $74.79 \pm 4.5$ & $70.87 \pm 5.2$ & $85.81 \pm 6.2^{a}$ & $66.16 \pm 5.2$ & $89.64 \pm 4.1^{\mathrm{a}}$ & $64.46 \pm 6.4$ \\
\hline $60 \mathrm{~min}$ & $56.19 \pm 6.1$ & $54.36 \pm 5.6$ & $82.62 \pm 2.5^{\mathrm{a}}$ & $50.8 \pm 3.5$ & $84.94 \pm 6.4^{\mathrm{a}}$ & $48.76 \pm 3.2$ \\
\hline $90 \mathrm{~min}$ & $44.79 \pm 5.2$ & $44.15 \pm 6.1$ & $76.09 \pm 3.5^{\mathrm{a}}$ & $39.42 \pm 4.1$ & $79.89 \pm 3.6^{a}$ & $41.52 \pm 2.7$ \\
\hline $120 \mathrm{~min}$ & $37.85 \pm 3.6$ & $34.1 \pm 4.1$ & $69.34 \pm 4.1^{\mathrm{a}}$ & $32.06 \pm 6.3$ & $73.69 \pm 2.8^{a}$ & $34.95 \pm 1.4$ \\
\hline
\end{tabular}

\begin{tabular}{lcccccc}
\hline CD4 $^{+}$ & \multicolumn{1}{c}{} \\
$0 \min$ & 100 & 100 & 100 & 100 & 100 & 100 \\
$30 \min$ & $90.83 \pm 5.6$ & $88.36 \pm 2.1$ & $92.15 \pm 7.1$ & $88.35 \pm 4.5$ & $95.4 \pm 5.6$ & $85.88 \pm 2.6$ \\
$60 \min$ & $86.22 \pm 2.3$ & $83.43 \pm 7.8$ & $91.47 \pm 7.4$ & $81.47 \pm 2.6$ & $94.09 \pm 5.1^{\mathrm{b}}$ & $78.59 \pm 4.9$ \\
$90 \min$ & $80.08 \pm 6.8$ & $78.05 \pm 4.8$ & $88.69 \pm 5.6$ & $75.98 \pm 3.9$ & $91.64 \pm 6.3^{\circ}$ & $76.86 \pm 3.7$ \\
$120 \min$ & $72.18 \pm 2.1$ & $68.48 \pm 3.4$ & $85.21 \pm 6.3^{\circ}$ & $67.89 \pm 1.8$ & $89.67 \pm 2.7^{\circ}$ & $71.11 \pm 2.5$
\end{tabular}

a $\mathrm{P}<0.05$ vs Non-treated, Rapa, Tac and Tac+Rapa

- $\mathrm{P}<0.05 \mathrm{vs}$ Tac and Tac+Rapa

c $P<0.05$ vs Non-treated, Tac and Tac+Rapa

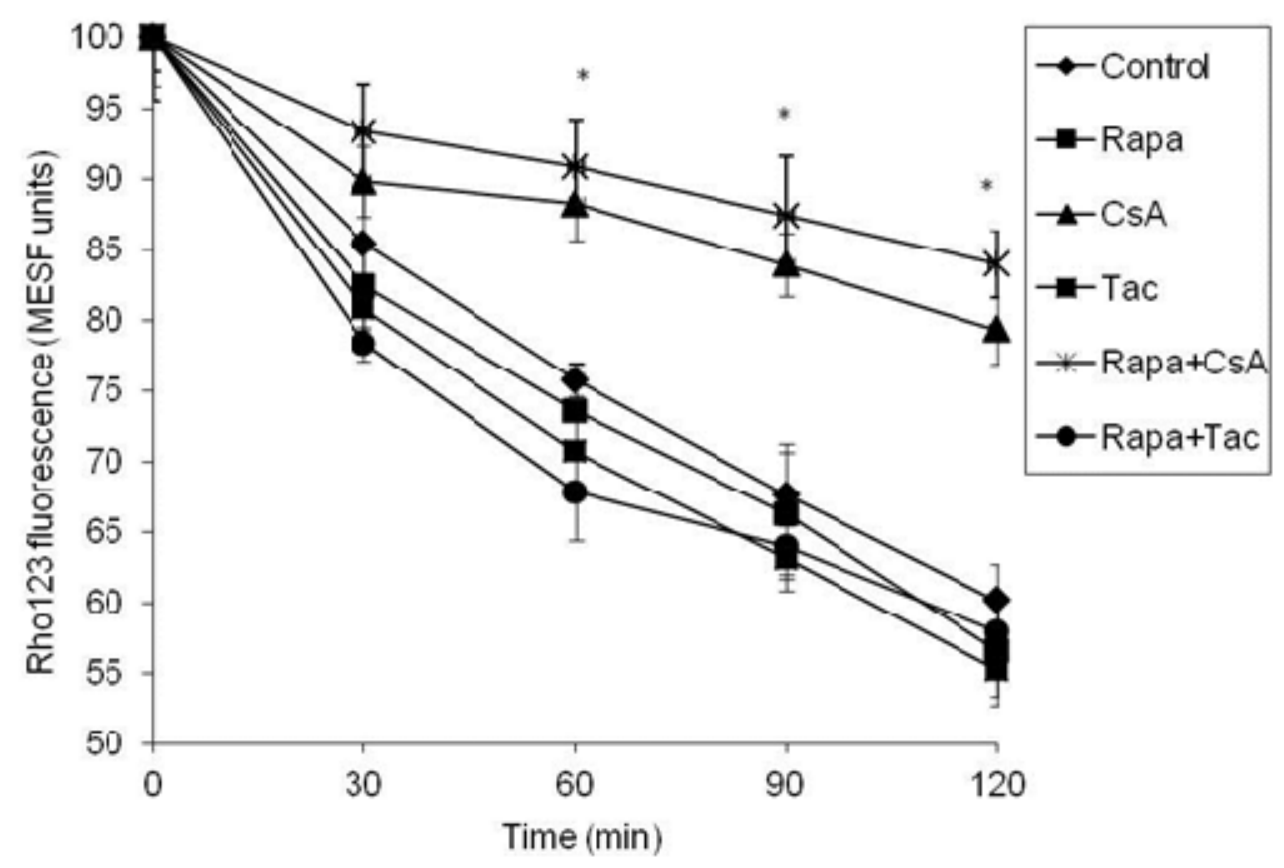

Figure 3. T-cell population kinetic profile. Drug-efflux curves were obtained after Rho123 uptake. Cells were incubated for up to $120 \mathrm{~min}$ at $37^{\circ} \mathrm{C} 5 \% \mathrm{CO}_{2}$. Kinetic profile of Rho123 extrusion was evaluated using different time points $(0,30,60,90$ and $120 \mathrm{~min})$ according to each immunosuppressive treatment. Arbitrary fluorescence units were transformed to calibrated MESF values and normalized $(* \mathrm{p}<0.001)$. 

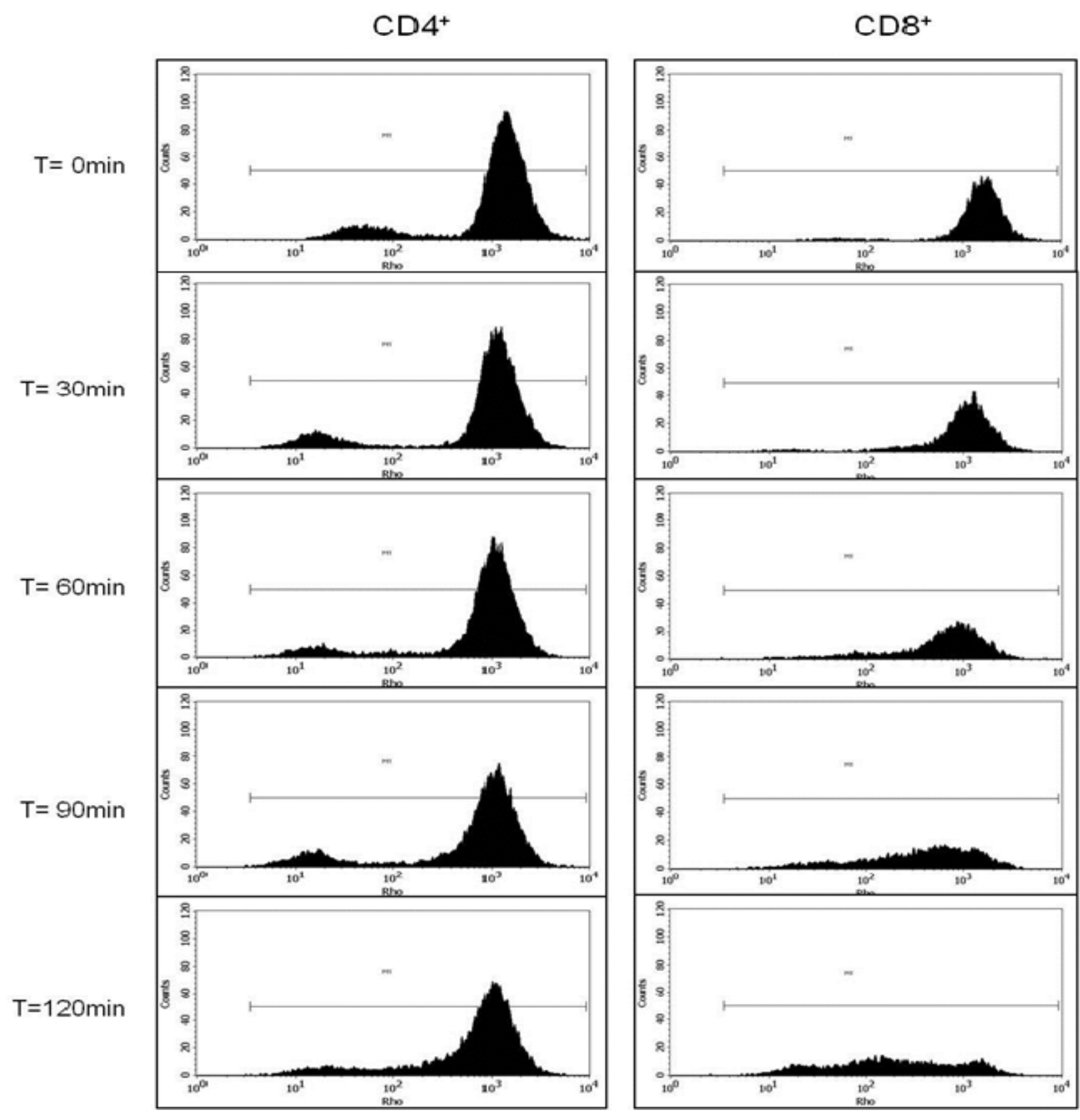

Figure 4. Representative histograms of the kinetic profile of Rho123 extrusion in CD $4^{+}$and $\mathrm{CD} 8^{+}$subsets. Ten thousand events of PBMCs were acquired for each assay. $\mathrm{N}=8$ different subjects for each subsets and immunosuppressants groups.

\section{Antigen-specific memory T-cell proliferation}

Pgp blockade using the specific inhibitor PSC833 showed a similar inhibition profile on lymphocyte proliferation as all the immunosupressants (Fig. 7). Proliferation of antigen-specific memory $\mathrm{CD}^{+}$ $\mathrm{T}$ cells was significantly abbrogated in groups treated with PSC833 and immunosuppressants compared to non-treated groups $(5-15 \%$ vs $30 \%$ of T-cell proliferation respectively, $\mathrm{p}<0.05)$. All immunosupressants in monotherapy inhibited Tcell proliferation in a similar degree as PSC833. Interestingly, both associations with Rapa (CsA+Rapa and Tac+Rapa) showed a further proliferation reduction compared with these immunosupressants in monotherapy. 


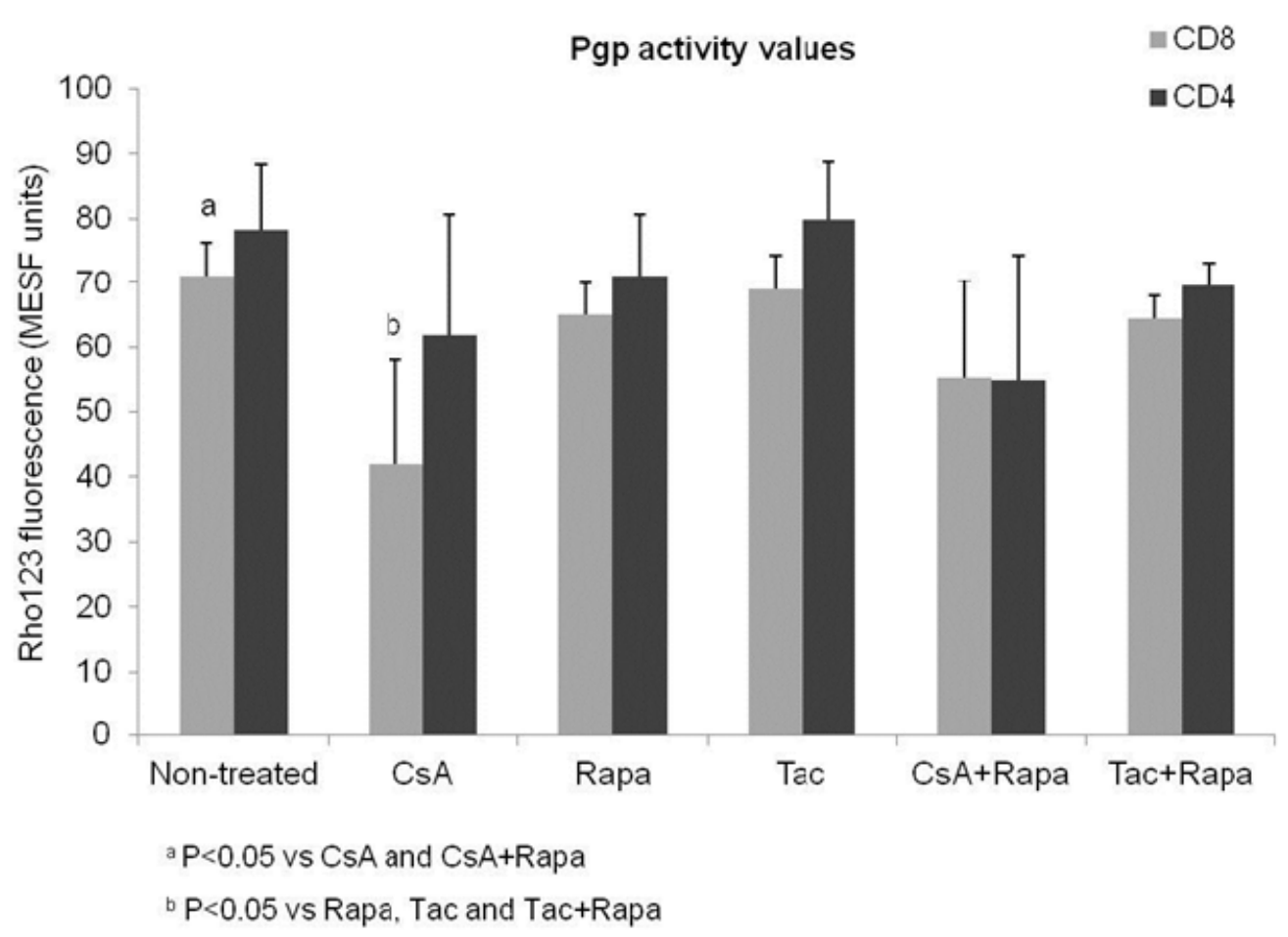

Figure 5. Pgp activity by flow cytometry analysis measured with MESF units of Rho123 fluorescence in CD4 ${ }^{+}$and $\mathrm{CD} 8^{+} \mathrm{T}$-cell subsets. $\mathrm{N}=8$ different subjects for each group. Any difference was observed among treatment groups in $\mathrm{CD}^{+}{ }^{+} \mathrm{T}$-cell subset.

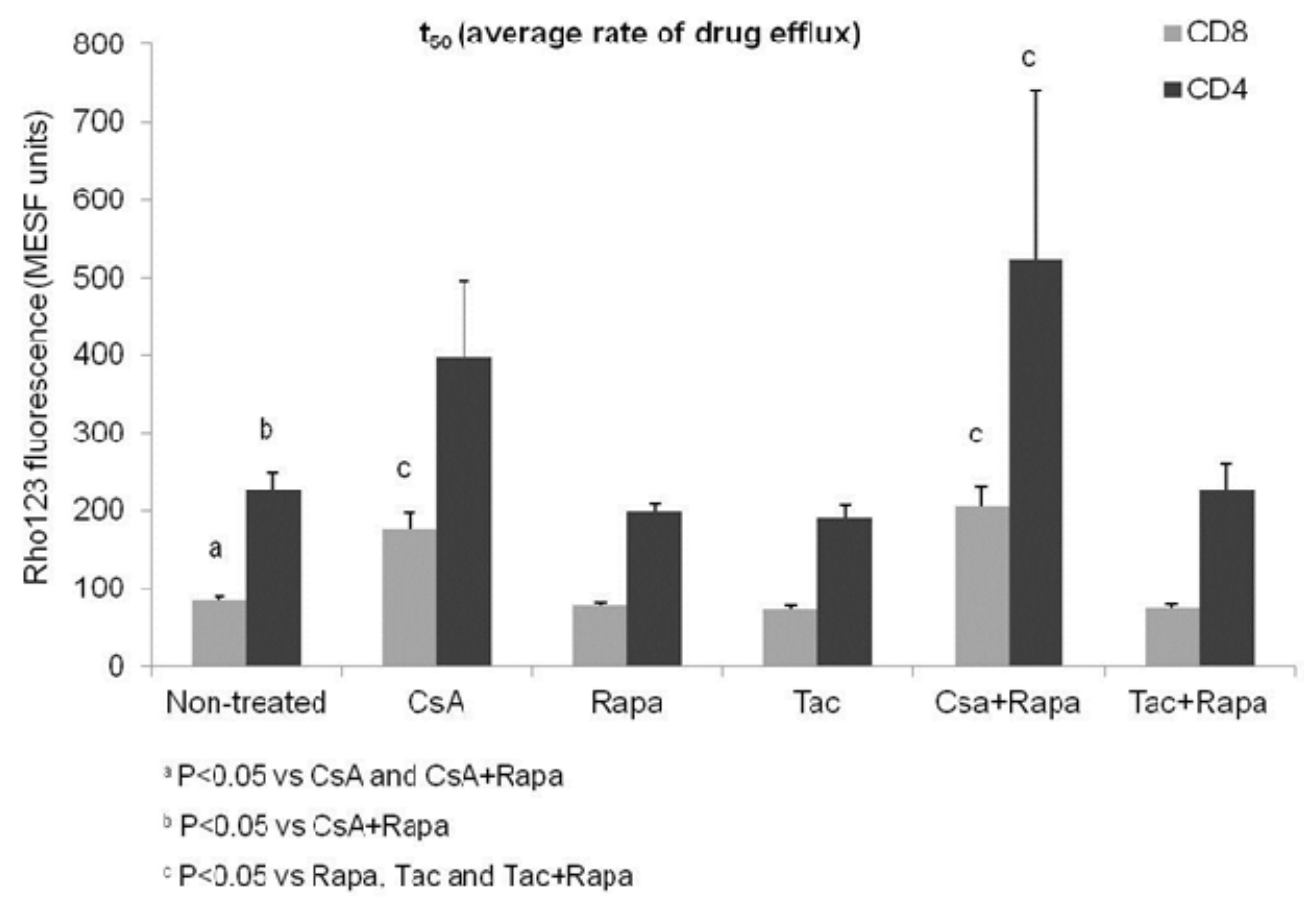

Figure 6. Pgp kinetic profile ( $\mathrm{t}_{50}$; average rate of drug efflux) by flow cytometry analysis in $\mathrm{CD} 4^{+}$and $\mathrm{CD} 8^{+} \mathrm{T}$-cell subsets. Arbitrary fluorescence units were transformed to calibrated MESF values. $\mathrm{N}=8$ different subjects for each group. 
In $\mathrm{CD}^{+}$and $\mathrm{CD}^{+}$T-cell subsets all immunosuppressant therapies and PSC833 diminished lymphocyte proliferation, and this effect was especially more evident in CD8 than CD4 T cells (25\% vs $15 \%$ of T-cell proliferation inhibition respectively, $\mathrm{p}<0.05)$. However, despite T-cell proliferation decreased in PSC833 group in $\mathrm{CD} 4$ and $\mathrm{CD} 8 \mathrm{~T}$ cells, there was only significant difference for CD8. Furthermore, in the $\mathrm{CD}^{+}$subset, both associations with Rapa showed a reduced proliferation compared with these immunosupressants in monotherapy, in a similar pattern as CD3 $\mathrm{T}$ cells, but in this case only Tac+Rapa achieved statistical differences $(\mathrm{p}<0.05)$.

\section{Cytokine secretion in MLR}

Th1 pro-inflammatory cytokines such as IFN- $\gamma$ and TNF- $\alpha$, were significantly reduced in all immunosuppressive therapies and PSC833-treated groups than in those non-treated $(\mathrm{p}<0.05)$. However, CsA group did not reach statistical significance in the IFN- $\gamma$ secretion, even it was significantly higher than all the other immunosuppressants and PSC833 $(\mathrm{p}<0.05)$. On the other hand, only Tac showed significantly lower TNF- $\alpha$ release compared to the other treatment groups $(\mathrm{p}<0.05)$ (Fig. 8). Regarding the Th2 cytokine profile, PSC 833 and the immunosuppressive therapies, except for CsA, diminished IL-6 secretion compared to the nontreated stimulated group. Furthermore, the two macrolides in monotheray showed a significant decrease compared with both drugs associated $(p<0.05)$. Concerning IL-10, rapamycin groups showed an important decrease in this cytokine secretion compared with the other groups, reflecting that Rapa plays an important role in the modulation of IL-10 (Fig. 8).

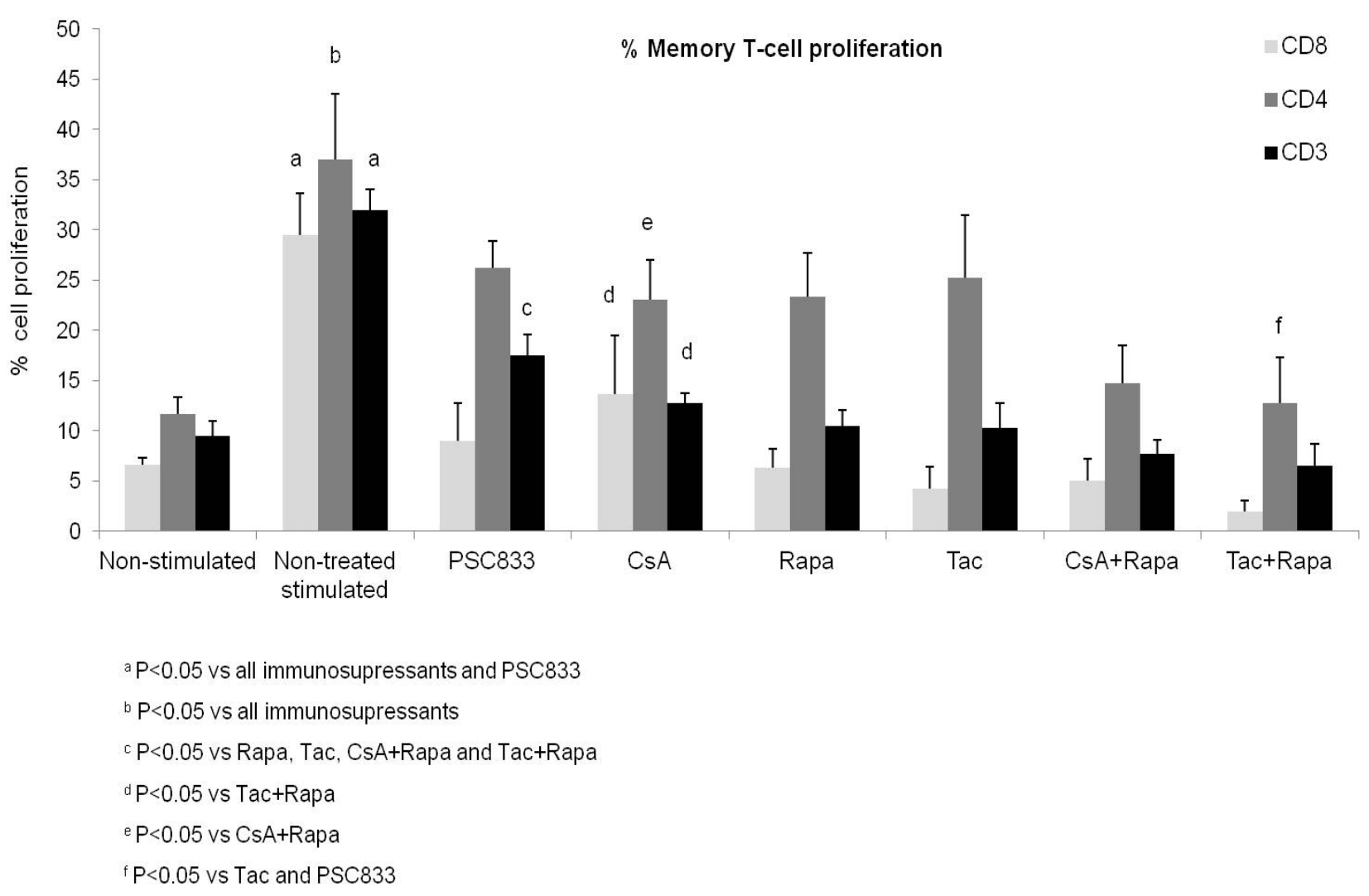

Figure 7. Antigen-specific memory T-cell proliferation under different immunosupressants and Pgp specific inhibitor (PSC833) in different T-cell subsets. Values are means (MESF) \pm SE. Experiments are representative of four independent assay. 

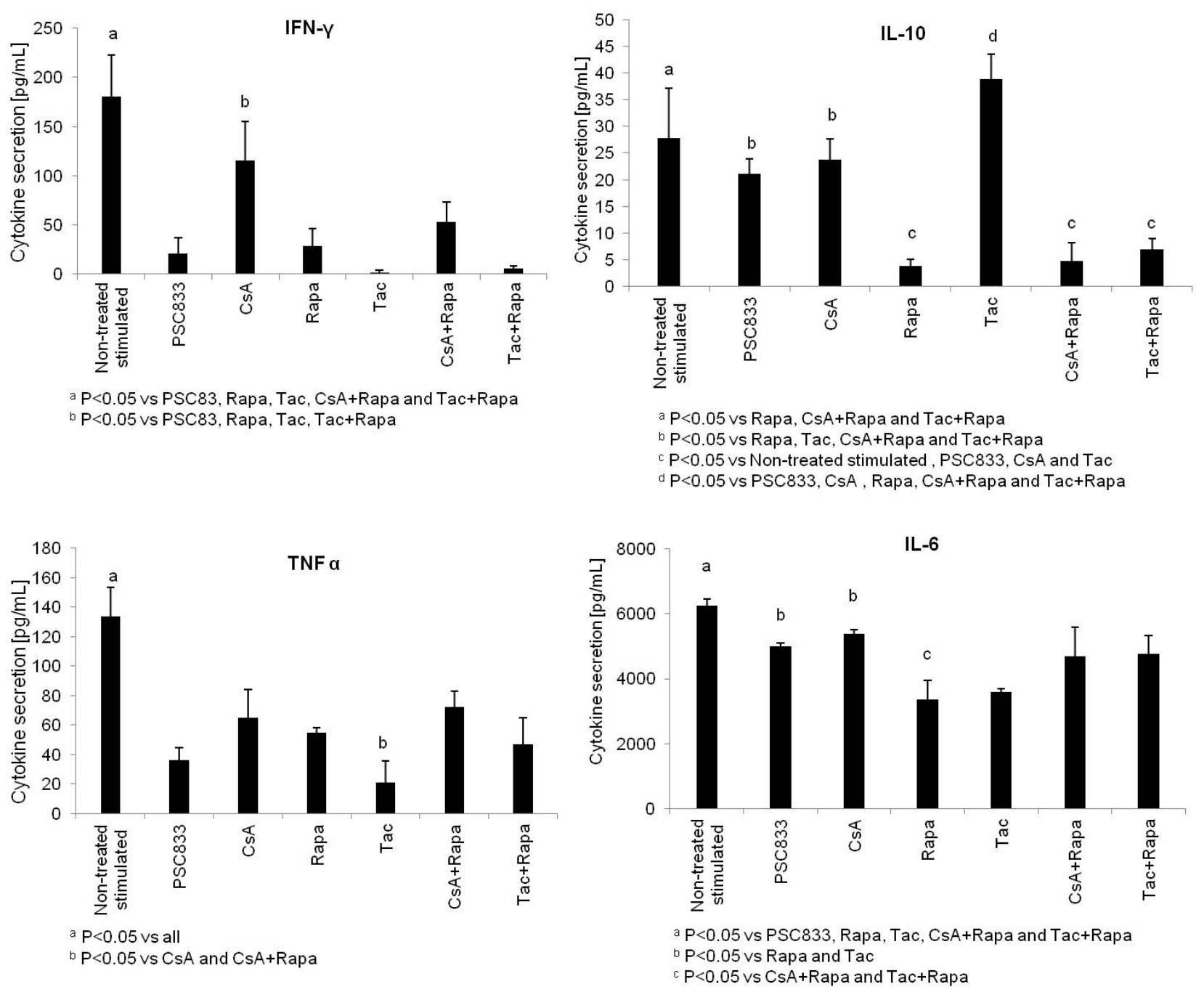

Figure 8. Cell cytokine analysis by flow cytometry into supernatants by PBMCs in MLR. Fluorescent bead assay (CBA Human Th1/Th2/Th17 kit). Experiments are representative of three independent assays.

\section{DISCUSSION}

Pgp is a functionally active efflux pump physiologically expressed in several tissues and peripheral blood mononuclear cells. Its role in pumping drugs out of the cells is widely known but its function in immunologic mechanisms is complex and still not fully understood. The crucial role of $\mathrm{ABC}$ transporters in lymphocyte survival and antigen presenting cell differentiation has been described (13). Pendse et al underlined the important immunoregulatory effects of Pglycoprotein-inhibiting agents, suggesting a promising novel Pgp therapeutic target for immune modulation in acute and chronic allograft rejection, and cell-mediated autoimmune disorders (29).

In our study, we analyzed the influence of immunosuppressive drugs on intracellular Rho123 uptake and the kinetic profile of Pgp activity in different lymphocyte subsets. Immunosuppressive agents are Pgp substrates and/or inhibitors that may influence the functional response of T cells (30). Our results demonstrated a significant decrease in Rho123 uptake in $T$ lymphocyte subsets treated with CsA, suggesting the role of Pgp not only in the efflux but also in the influx of Pgp substrates inside the cells. In addition, our results illustrate the inhibitory effect of CsA in blocking Pgp function not only in the 
efflux but also in the influx of Pgp substrates. On the other hand, Pgp activity in T cells treated with both macrolides showed a similar profile to cells without immunosuppressive drugs; therefore, at the concentrations used, Rapa and Tac did not modify Pgp activity.

When the efflux of Rho123 was analyzed, T cells treated with CsA with or without Rapa presented a slower kinetic profile compared to Tac and Rapa alone or associated, confirming the potent inhibitory effect of CsA on Pgp compared to the other immunosuppressors. Cells treated with CsA spent 2-fold minutes to efflux $50 \%$ of the Rho123 as compared to the macrolide groups. Furthermore, the time required to extrude Rho123 was longer in $\mathrm{T}$ cells incubated with CsA plus Rapa than CsA alone, suggesting an additive inhibitory effect of rapamycin on Pgp when combined with CsA. The association, Tac and Rapa, and both immunosupressants separately, lasted the same time to efflux $50 \%$ of the Rho123 as took the non-treated non-stimulated group. In fact, rapamycin and tacrolimus affected Pgp activity but they did not modulate Pgp function at pre-established doses. Similarly to what was previously reported by Pawarode and collegues (25) here, we show that CsA seems to be a broadspectrum MDR modulator impairing drug transport at the clinically achievable concentration of $2.5 \mu \mathrm{M}$, tacrolimus enhanced cellular drug uptake at $1 \mu \mathrm{M}$, but not at its clinically achievable concentration $(0.1 \mu \mathrm{M})$. Rapamycin exerts the optimal effect of enhancing cellular drug uptake at $2.5 \mu \mathrm{M}$, but it was not effective at its clinically achievable concentration of $0.25 \mu \mathrm{M}$.

The specific role of Pgp modulators and their kinetic profile is thus essential to fully characterize and approach the broad properties of immunosuppressive drugs (31), Laurent $\mathrm{G}$ et al (32) and Gupta et al (33) clearly showed that the expression of Pgp was higher in $\mathrm{CD}^{+}$than in $\mathrm{CD} 8^{+} \mathrm{T}$ cells. Functionally, Pgp was more efficient in the $\mathrm{CD} 8^{+}$subpopulation. In our study we found higher Rho123 uptake and efflux in $\mathrm{CD}^{+} \mathrm{T}$ cells than in $\mathrm{CD}^{+} \mathrm{T}$ cells, suggesting that both influx and efflux of Pgp substrates showed a different modulation depending on the T-cell subset studied. Furthermore and, in line with previously published results (33), the kinetic of Rho123 extrusion was also remarkebly faster in $\mathrm{CD}^{+}$than in $\mathrm{CD}^{+}$subsets suggesting a physiologic role of Pgp within the cytotoxic $\mathrm{T}$ lymphocyte subset. Pgp function was modified after T-cell pre-tretament with immunosuppressors showing slower Rho extrussion in both CsA groups compared with macrolide groups. The Pgp kinetic was also faster in $\mathrm{CD} 8^{+} \mathrm{T}$ cells than $\mathrm{CD} 4^{+} \mathrm{T}$ cells.

Nowadays the interest of the role of $\mathrm{ABC}$ transporters is increasing. Their extruding function and/or their inhibitory functions could be an interesting new pharmacodynamic target. Recently, Brennan et al examined a new molecule (LIM-0705) designed to activate specific $\mathrm{ABC}$ transporters in the kidney and liver, facilitating the export of Tac out of vulnerable cells in order to reduce toxicity while preserving its immunosuppressive effect. The increase in the intra-lymphocyte drug concentration is associated with more effective inhibition of lymphocyte proliferation by CsA in vitro, these results could translate in vivo into more effective protection against graft rejection (34). Upon secondary exposure to alloantigen, both $\mathrm{CD}^{+}$and $\mathrm{CD} 8^{+}$ memory $\mathrm{T}$ cells rapidly proliferate and differentiate into effector cells. It is well known, that CNIs are the most robust drugs to suppress alloreactive effector/memory $\mathrm{T}$ cells (35). Therefore, we studied whether both Pgp blocker and the different immunosuppressants showed an efficient inhibitory effect on alloreactive memory $\mathrm{T}$ cells. Our results proved that Pgp blockade and immmunosuppressants resulted mainly in $\mathrm{CD} 8^{+}$ lymphocyte inhibition diminishing lymphocyte proliferation as $\mathrm{CD}^{+}$subset. In contrast in $\mathrm{CD} 4^{+}$ T-cell proliferation was slightly inhibited by PSC833 and all immunosuppressants. Considering that antigen-specific memory $\mathrm{T}$ cells have less sensibility to classical immunosuppressive agents being the main responsible of acute cellular rejection episodes after transplantation these results have relevance in clinical renal transplantation.

Based on its known function as a transmembrane transporter (36), Pgp has been proposed to facilitate the membrane transport and/or release of cytokines. In our study we measured cytokine secretion in MLR with different immunosuppressants and specific Pgp inhibitor. Our data showed that pro-inflammatory Th1 cytokines secretion, IFN- $\gamma$ and TNF- $\alpha$, were significantly reduced in all treatment groups, pointing up the maximum response after Tac exposition. On the other hand, Th2 cytokine response by IL-6 was minimized in all immunosupressants except for CsA and PSC833 compared with non-treated stimulated group. On the other hand, rapamycin in monotherapy or associated was the only immunosupressant able to 
reduce IL-10 secretion, reflecting the important role of Rapa in IL-10 modulation.

In summary, Pgp activity appears to be modulated depending on the immunosupressor treatment with faster Pgp kinetic in $\mathrm{CD}^{+}$than $\mathrm{CD}^{+} \mathrm{T}$-cell subsets. Our data indicate that CsA inhibit Pgp activity and T-cell function being the $\mathrm{CD} 8^{+} \mathrm{T}$ cells more susceptible to this effect than $\mathrm{CD}^{+} \mathrm{T}$ cells. On the other hand, immunosuppressants significantly reduced T-cell proliferation of $\mathrm{CD}^{+}$and $\mathrm{CD} 8^{+}$subsets. Our results underline the importance of the immunoregulatory effects of Pgp in T-cell activation and in immunosuppressive regimens. Thus, looking for new strategies to target this Tcell subset population is necessary to further delve into potential mechanisms of Pgp in T-cell activation. The inhibition of this protein could be a novel therapeutic target in order to avoid allograft rejection in solid organ transplantation.

\section{ACKNOWLEDGMENTS}

The authors are particularly grateful to all the healthy volunteers who contributed to the study. We are especially grateful to Eva Julià from Servei Cientific-tècnic team for their immeasurable help with FACS techniques. We thank Novartis in Basel for kindly providing PSC833. This research was supported by grants from Instituto de Salud Carlos III/FIS (PI07/078). Núria Lloberas is researcher from ISCIII/FIS (CP06/00067) and Inés Llaudó is a fellow of Fundació Catalana de Trasplantament.

\section{REFERENCES}

1. Brenner SS, Klotz U. P-glycoprotein function in the elderly. Eur J Clin Pharmacol, 2004; 60(2):97102 .

2. Lucia MB, Rutella S, Leone G, Vella S, Cauda R. HIV-protease inhibitors contribute to Pglycoprotein efflux function defect in peripheral blood lymphocytes from HIV-positive patients receiving HAART. J Acquir Immune Defic Syndr, 2001; 27(4):321-330.

3. Rao US, Scarborough GA. Direct demonstration of high affinity interactions of immunosuppressant drugs with the drug binding site of the human Pglycoprotein. Mol Pharmacol, 1994; 45(4):773776.

4. Wang Y, Hao D, Stein WD, Yang L. A kinetic study of Rhodamine123 pumping by Pglycoprotein. Biochim Biophys Acta, 2006; 1758(10):1671-1676.

5. Gottesman MM, Ling V. The molecular basis of multidrug resistance in cancer: the early years of
P-glycoprotein research. FEBS Lett, 2006; 580(4):998-1009.

6. Frank MH, Denton MD, Alexander SI, Khoury SJ, Sayegh MH, Briscoe DM. Specific MDR1. Pglycoprotein blockade inhibits human alloimmune $\mathrm{T}$ cell activation in vitro. $\mathrm{J}$ Immunol, 2001; 166(4):2451-2459.

7. Shirasaka Y, Onishi Y, Sakurai A, Nakagawa H, Ishikawa T, Yamashita S. Evaluation of human Pglycoprotein (MDR1/ABCB1) ATPase activity assay method by comparing with in vitro transport measurements: Michaelis-Menten kinetic analysis to estimate the affinity of P-glycoprotein to drugs. Biol Pharm Bull, 2006; 29(12):2465-2471.

8. Grude P, Boleslawski E, Conti F, Chouzenoux S, Calmus Y. MDR1 gene expression in peripheral blood mononuclear cells after liver transplantation. Transplantation, 2002; 73(11):1824-1828.

9. Meaden ER, Hoggard PG, Khoo SH, Back DJ. Determination of P-gp and MRP1 expression and function in peripheral blood mononuclear cells in vivo. J Immunol Methods, 2002; 262(1-2):159165.

10. Ling V. Multidrug resistance: molecular mechanisms and clinical relevance. Cancer Chemother Pharmacol, 1997; 40 Suppl:S3-8.

11. Gottesman MM, Pastan I. Biochemistry of multidrug resistance mediated by the multidrug transporter. Annu Rev Biochem, 1993; 62:385427.

12. Pendse SS, Behjati S, Schatton T, Izawa A, Sayegh MH, Frank MH. P-glycoprotein functions as a differentiation switch in antigen presenting cell maturation. Am J Transplant, 2006; 6(12):2884-2893.

13. van de Ven $\mathrm{R}$, de Jong MC, Reurs AW, Schoonderwoerd AJ, Jansen G, Hooijberg JH, Scheffer GL, de Gruijl TD, Scheper RJ. Dendritic cells require multidrug resistance protein 1 (ABCC1) transporter activity for differentiation. J Immunol, 2006; 176(9):5191-5198.

14. Donnenberg VS, Burckart GJ, Griffith BP, Jain $\mathrm{AB}$, Zeevi A, Berg AD. P-glycoprotein (P-gp) is upregulated in peripheral T-cell subsets from solid organ transplant recipients. J Clin Pharmacol, 2001; 41(12):1271-1279.

15. Lemahieu WP, Maes BD, Verbeke K, Vanrenterghem Y. CYP3A4 and P-glycoprotein activity in healthy controls and transplant patients on cyclosporin vs. tacrolimus vs. sirolimus. Am J Transplant, 2004; 4(9):1514-1522.

16. del Moral RG, Andujar M, Ramirez C, GomezMorales M, Masseroli M, Aguilar M, Olmo A, Arrebola F, Guillen M, Garcia-Chicano MJ, Nogales FF, O'Valle F. Chronic cyclosporin A nephrotoxicity, P-glycoprotein overexpression, and relationships with intrarenal angiotensin II deposits. Am J Pathol, 1997; 51(6):1705-1714.

17. Morales JM, Wramner L, Kreis H, Durand D, Campistol JM, Andres A, Arenas J, Negre E, 
Burke JT, Groth CG. Sirolimus does not exhibit nephrotoxicity compared to cyclosporine in renal transplant recipients. Am J Transplant, 2002; 2(5):436-442.

18. Anglicheau D, Pallet N, Rabant M, Marquet $P$, Cassinat B, Meria $\mathrm{P}$, Beaune $\mathrm{P}$, Legendre $\mathrm{C}$, Thervet E. Role of P-glycoprotein in cyclosporine cytotoxicity in the cyclosporine-sirolimus interaction. Kidney Int, 2006; 70(6):1019-1025.

19. Scott LJ, McKeage K, Keam SJ, Plosker GL. Tacrolimus: a further update of its use in the management of organ transplantation. Drugs, 2003; 63(12):1247-1297.

20. Heidecke CD, Nicolaus C, Stadler J, Florack G, Bollschweiler E, Holscher M. Measurement of cyclosporine bioactivity in serum of renal transplant recipients: development and comparison with RIA. Transplant Proc, 1987; 19(1 Pt 2):17341736.

21. Kahan BD. Individualization of cyclosporine therapy using pharmacokinetic and pharmacodynamic parameters. Transplantation, 1985; 40(5):457-476.

22. Podder H, Stepkowski SM, Napoli KL, Clark J, Verani RR, Chou TC, Kahan BD. Pharmacokinetic interactions augment toxicities of sirolimus/cyclosporine combinations. J Am Soc Nephrol, 2001; 12(5):1059-1071.

23. Lloberas N, Torras J, Alperovich G, Cruzado JM, Gimenez-Bonafe P, Herrero-Fresneda I, Franquesa M, Rama I, Grinyo JM. Different renal toxicity profiles in the association of cyclosporine and tacrolimus with sirolimus in rats. Nephrol Dial Transplant, 2008; 23(10):3111-3119.

24. Chiva-Blanch G, Gimenez-Bonafe P, Llaudo I, Torras J, Cruzado JM, Petriz J, Castano E, Franquesa M, Herrero-Fresneda I, Tortosa A, Rama I, Bestard O, Grinyo JM and Lloberas N. Different storing and processing conditions of human lymphocytes do not alter P-glycoprotein rhodamine 123 efflux. J Pharm Pharm Sci, 2009; 12(3):357-366.

25. Pawarode A, Shukla S, Minderman H, Fricke SM, Pinder EM, O'Loughlin KL, Ambudkar SV, Baer MR. Differential effects of the immunosuppressive agents cyclosporin A, tacrolimus and sirolimus on drug transport by multidrug resistance proteins. Cancer Chemother Pharmacol, 2007; 60(2):179-188.

26. Parasrampuria DA, Lantz MV, Birnbaum JL, Vincenti FG, Benet LZ. Effect of calcineurin inhibitor therapy on P-gp expression and function in lymphocytes of renal transplant patients: a preliminary evaluation. J Clin Pharmacol, 2002; 42(3):304-311.

27. Donnenberg VS, Wilson JW, Burckart GJ, Zeevi A, Iacono A, Donnenberg AD. Measurement of basal, substrate induced and total P-glycoprotein activity in bronchoalveolar lavage T-cell subsets. Cytometry A, 2004; 57(2):75-85.
28. Chen JC, Chang ML, Muench MO. A kinetic study of the murine mixed lymphocyte reaction by 5,6-carboxyfluorescein diacetate succinimidyl ester labeling. J Immunol Methods, 2003; 279(12):123-133.

29. Pendse S, Sayegh MH, Frank MH. P-glycoprotein-a novel therapeutic target for immunomodulation in clinical transplantation and autoimmunity? Curr Drug Targets, 2003; 4(6):469-476.

30. Donnenberg VS, Burckart GJ, Zeevi A, Griffith $\mathrm{BP}$, Iacono A, McCurry $\mathrm{KR}$, Wilson JW, Donnenberg AD. P-glycoprotein activity is decreased in CD4+ but not CD8+ lung allograftinfiltrating $\mathrm{T}$ cells during acute cellular rejection. Transplantation, 2004; 77(11):1699-1706.

31. Parasrampuria DA, Lantz MV, Benet LZ. A human lymphocyte based ex vivo assay to study the effect of drugs on P-glycoprotein (P-gp) function. Pharm Res, 2001; 18(1):39-44.

32. Demur C, Muller C, Cassar G, Bousquet C, Laroche M, Laurent G. Acute myeloid leukemia cells with low P-glycoprotein expression and high rhodamine 123 efflux capacity display high clonogenicity. Leukemia, 1998; 12(2):192-199.

33. Gupta S, Kim CH, Tsuruo T, Gollapudi S. Preferential expression and activity of multidrug resistance gene 1 product (P-glycoprotein), a functionally active efflux pump, in human CD8+ $\mathrm{T}$ cells: a role in cytotoxic effector function. $\mathrm{J}$ Clin Immunol, 1992; 12(6):451-458.

34. Singh D, Alexander J, Owen A, Rustom R, Bone M, Hammad A, Roberts N, Park K, Pirmohamed M. Whole-blood cultures from renal-transplant patients stimulated ex vivo show that the effects of cyclosporine on lymphocyte proliferation are related to P-glycoprotein expression. Transplantation, 2004; 77(4):557-561.

35. Wu Z, Bensinger SJ, Zhang J, Chen C, Yuan X, Huang X, Markmann JF, Kassaee A, Rosengard BR, Hancock WW, Sayegh MH, Turka LA. Homeostatic proliferation is a barrier to transplantation tolerance. Nat Med, 2004; 10(1):87-92.

36. Wang H, Hosiawa KA, Min W, Yang J, Zhang X, Garcia B, Ichim TE, Zhou D, Lian D, Kelvin DJ, Zhong R. Cytokines regulate the pattern of rejection and susceptibility to cyclosporine therapy in different mouse recipient strains after cardiac allografting. J Immunol, 2003;171(7):3823-3836. 